\title{
EARLY PREGNANCY AND ENDOTHELIAL DYSFUNCTION
}

DOI: 10.36740/WLek202004122

\author{
Lyudmyla V. Dubyk, Oleksandr M. Yuzko, Nataliia V. Chernetska, Tetiana R. Kolotylo \\ HSEI BUKOVINIAN STATE MEDICAL UNIVERSITY, CHERNIVTSI, UKRAINE
}

\begin{abstract}
The aim is to analyze the value of endothelial dysfunction markers during pregnancy.

Materials and methods: We have examined 153 pregnant women to identify endothelial dysfunction markers of endothelin-1, nitrogen oxide (NO) that have been studied using immunoenzymometric sets for an uncomplicated and complicated pregnancy.

Results: We found that the concentration of endothelin-1 repeatedly exceeded the rates in pregnant women with miscarriages than during physiological pregnancy. The diametrically opposite pattern concerns the level of nitrogen oxide. These changes in the markers of the functional state of the endothelin indicate the development of the dysfunction of this system in women with the pathology of pregnancy.

Conclusions: Consequently, endothelial dysfunction can be considered to be one of the reasons for miscarriage in the examined women. Therefore, the definition of markers of endothelial dysfunction has prognostic value.
\end{abstract}

KEY WORDS: miscarriage, endothelial dysfunction, endothelin-1, nitrogen oxide

Wiad Lek. 2020;73(4):743-745

\section{INTRODUCTION}

For many years, the endothelium has been considered a barrier that separated the blood from the perivascular flow. However, long-term studies have shown that it plays an important role in providing hemostasis and is the largest endocrine gland [1]. The endothelium covers the inside of the heart and blood vessels and constantly synthesizes a large number of biologically active substances that possess a variety of properties [2]. Substances secreted by endothelium can be divided into three groups: vasodilators, vasoconstrictors, and others [3]. The main vasodilator is nitric oxide (NO), which is synthesized by endothelial NO-synthetase from the amino acid arginine $[3,4]$. Endothelin-1 has the contractile effect on the tone of vascular smooth muscle.

Functioning of the endothelium lies in the balance of opposite effects: strengthening-weakening of the vascular tone, aggregation-disaggregation of blood cells, increase-reduction of the number of vascular cells. In each case, the result is due to the concentration of synthesized substances, between which a strict dependence and equilibrium are established. The violation of this equilibrium is endothelial dysfunction (ED). ED leads to changes in vascular reactivity, activation of the cascade of intravascular coagulation and violation of vascular integrity. The state of the endothelial system is important for the development of pregnancy.

Certain compensatory and adaptive conditions are known to be created in the body of a pregnant woman, which is necessary both for the normal formation of the fetoplacental complex and for limitation of blood loss during childbirth. According to researchers, hemostatic changes are observed in $80 \%$ of patients with the loss of pregnancy in early terms, and they contribute to hypercoagulation [5].

The state of the endothelial system is important for the development of pregnancy.

\section{THE AIM}

The aim is to analyze the value of endothelial dysfunction markers during pregnancy.

\section{MATERIALS AND METHODS}

For the purpose of studying the endothelial dysfunction in women with miscarriage, 153 patients were examined, among them: 30 - with uncomplicated pregnancy in the period of 6-12 weeks (group I - control), 60 - with the threat of abortion (group II), 34 with spontaneous abortion (group III) and 29 with non-developing pregnancy (group IV).

We have identified the markers of endothelial dysfunction, namely endothelin-1, nitrogen oxide (NO) using immunoenzymometric systems. Quantitative determination of the large endothelin in serum has been carried out with the help of the immunoenzymometric set of CJSC "BioHimMak" (Russia). The instability of NO makes it impossible for standard methods to define it. Test system for NO determination (CJSC "BioHimMak", (R\&D Systems, TotalNitricOxideAssay) is based on the principle of converting nitrate $\left(\mathrm{NO}_{3}^{-}\right)$into nitrite $\left(\mathrm{NO}_{2}^{-}\right)$in the reaction catalyzed by nitrate reductase enzyme. 
Table I. Indices of endothelial dysfunction in women of different groups $(\mathrm{M} \pm \mathrm{m})$

\begin{tabular}{ccc}
\hline Index & Median & $\begin{array}{c}\text { Interquartile } \\
\text { scale [25\%; } \\
\mathbf{7 5} \%]\end{array}$ \\
\hline AIAT, od/I & 53,5 & {$[39,4 ; 88,3]$} \\
\hline AcAT, od/I & 45,0 & {$[36,8 ; 70,6]$} \\
\hline Total bilirubin, Mcmole/l & 27,0 & {$[12,0 ; 49,0]$} \\
\hline Alkaline phosphatase, mole/l & 131,0 & {$[94,6 ; 192,2]$} \\
\hline GGTP, mole/l & 72,5 & {$[47,4 ; 139,7]$} \\
\hline Total protein, g/l & 75,0 & {$[68,0 ; 80,5]$} \\
\hline
\end{tabular}

\section{RESULTS AND DISCUSSION}

It has been found that both of the investigated parameters of endothelial dysfunction were subjected to significant changes (Table I, Fig. 1, 2). Thus, in the representatives of group II (pregnant women with a threat of abortion), the concentration of endothelin-1 repeatedly exceeded theindices during physiological pregnancy $(10.46 \pm 1.37)$ $\mathrm{pmol} / \mathrm{l}$ at the risk of miscarriage, $(14.72 \pm 2.98) \mathrm{pmol} / \mathrm{l}$ in women with involuntary abortion and $(16.90 \pm 3.86)$ $\mathrm{pmol} / \mathrm{l}$ in case of non-developing pregnancy (in norm -
$(3.38 \pm 0.83)$ pmol/l). It is important that the level of the indicated marker of endothelial dysfunction between groups of women with different variants of non-pregnancy, despite some variations, did not differ statistically. Thus, the concentration of the indicated marker also significantly increased together with the development of the pathology of pregnancy

The diametrically opposite regularity has been related to the level of nitrogen oxide. Thus, in pregnant women with a threat of miscarriage, the level of this marker decreased to $(11.23 \pm 0.86) \mu \mathrm{mol} / \mathrm{l}$, which is significantly less than normal statistically $(19.42 \pm 1.15) \mu \mathrm{mol} / \mathrm{l}$, it decreased more than twice in case of spontaneous abortion, to $(9,35$ $\pm 0,92) \mu \mathrm{mol} / \mathrm{l}$, and in persons whose pregnancy did not develop - to $(10,48 \pm 1,03) \mu \mathrm{mol} / \mathrm{l}$. The difference between the values of nitric oxide in case of the threat of spontaneous abortion, already implemented in miscarriage and in non-developing pregnancy, is statistically not significant. The indicated decrease in the level of NO indicates an increase in blood coagulation potential (hypercoagulation).

Thus, an increase in the concentration of endothelin-1 and a decrease in the level of nitric oxide in the blood indicates the development of the endothelial dysfunction
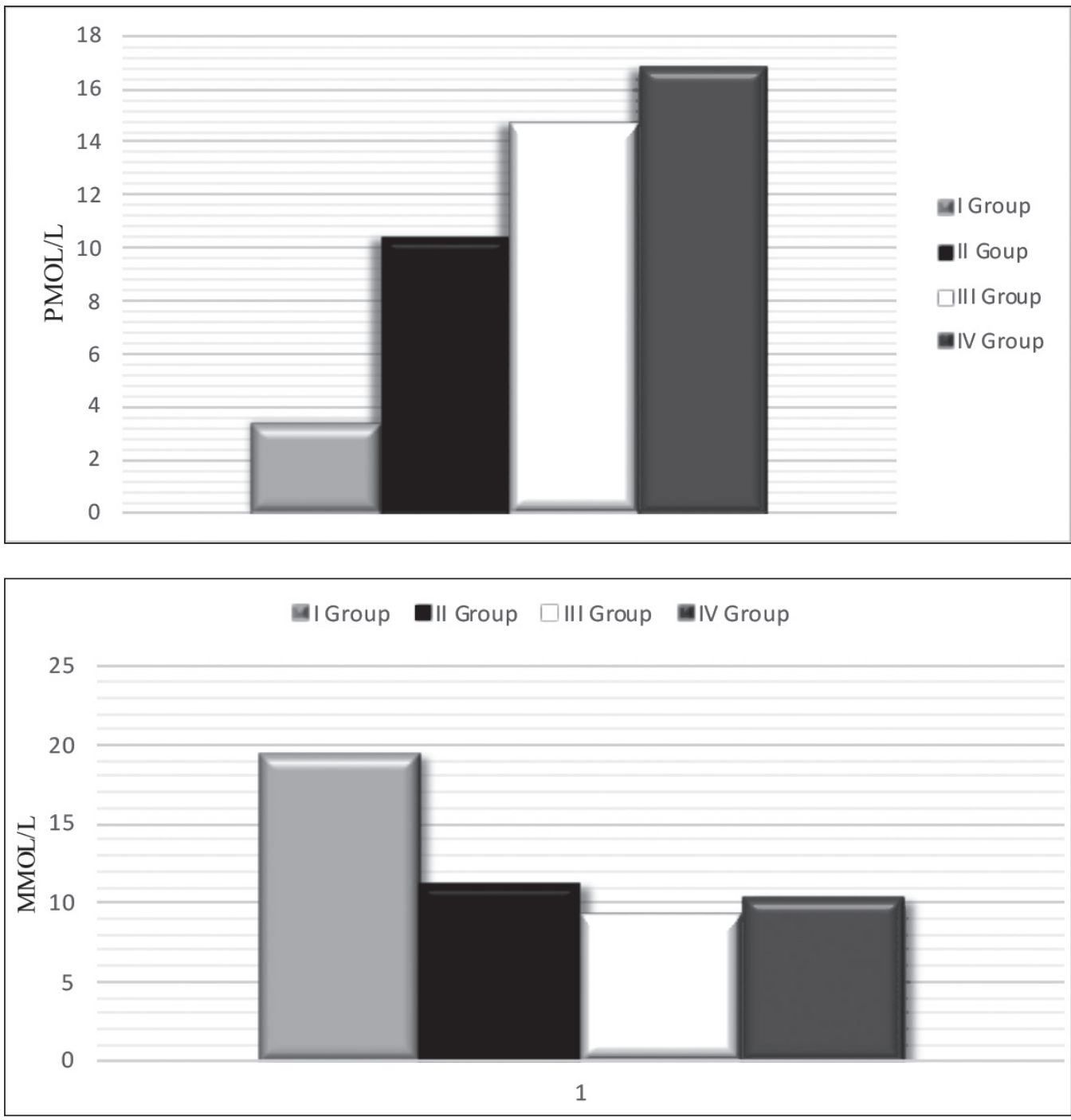

Fig. 1. The level of endothelin-1 in women with uncomplicated pregnancy and various variants of its pathology.

Fig. 2. The concentration of nitric oxide in women with uncomplicated pregnancy and various variants of its pathology. 
in women with the pathology of pregnancy. The indicated decrease in the concentration of nitric oxide, which is the main stimulant of the formation of cGMP, as well as an increase in the level of endothelin-1, leads to a decrease in the amount of cGMP, which increases the calcium content in the platelets and smooth muscle [6]. Calcium ions are mandatory participants in all phases of hemostasis and muscle contraction. Therefore, the drop in nitric oxide levels can lead to vasoconstriction in the uterine vessels and to the activation of platelet aggregation, and ultimately to the miscarriage.

\section{CONCLUSIONS}

1. Studies have shown that there is a tendency for multiple raising of the concentration of endothelin- 1 in women with a risk of miscarriage, with spontaneous abortion and non-developing pregnancy in comparison with the indices in case of physiological pregnancy.

2. At the time of the survey, changes in the level of NO have been detected, namely, a significant decrease in most patients with early pregnancy losses.

3 . The indicated alterations in endothelin-1 and NO levels indicate an increase in blood coagulation potential (hypercoagulation) and can lead to vasoconstriction in the uterine vessels and to the activation of platelet aggregation, and ultimately to the miscarriage.

4. Since the above changes in the data of biologically active substances are a reflection of the activity of endothelium, the endothelial dysfunction can be considered to be one of the reasons for miscarriages in the examined women.

5. Therefore, the definition of endothelial dysfunction markers has prognostic value and will help to reduce the number of perinatal losses.

\section{REFERENCES}

1. Biletskyi S.V., Boiko V.V., Petrynych O.A., et al. Endothelial dysfunction and arterial hypertension (literature review): Clinical and experimental pathology. 2017; XVI, 1 (59): 160-163.
2. Boger R.H. The pharmacodynamics of L-arginine. J. Nutr. 2007; 137: 1650-1655.

3. Luscher T.F. Endothelins and endothelin receptor antagonists; therapeutic considerations for a novel class of cardiovascular drugs. Circulation. 2000; 102: 2434-2440.

4. Babushkina A.V. L-arginine in terms of evidence-based medicine. Ukr. med. Periodical. 2009; 6 (74): 1-6.

5. Olusola A.D. Endothelial dysfunction in the genesis of early reproductive losses. Obstetrics and gynecology. 2012: 22.

6. Petrishchev N.N., Vlasov T.D. Physiology and pathophysiology of endothelium. Endothelial dysfunction. Causes, mechanisms, pharmacological correction. Publishing house of St. Petersburg State Medical University. 2003; 4-38.

\section{ORCID and contributionship:}

Lyudmyla V. Dubyk - 0000-0001-8307-1733 A,B,C,D

Oleksandr M. Yuzko - 0000-0003-1270-9095 A,D,E,F

Nataliia V. Chernetska - 0000-0002-5156-1313 ${ }^{B, C, D}$

Tetiana R. Kolotylo - 0000-0002-9492-7661 ${ }^{B, C, D}$

\section{Conflicts of interest:}

Authors declare no conflict of interest.

\section{CORRESPONDING AUTHOR Tetiana R. Kolotylo \\ HSEl Bukovinian state medical university \\ Teatralna square 2, Chernivtsi, Ukraine \\ tel: +0664669273 \\ e-mail: taniakolotylo15@gmail.com}

Received: 12.06 .2019

Accepted: 25.02 .2020

A - Work concept and design, B - Data collection and analysis, C - Responsibility for statistical analysis, D-Writing the article, E-Critical review, $\mathbf{F}$ - Final approval of the article 